\title{
Influence of char composition and inorganics on catalytic activity of char from biomass gasification
}

\author{
Naomi B. Klinghoffer ${ }^{\mathrm{a}, 1}$, Marco J. Castaldi ${ }^{\mathrm{a}, *}$, Ange Nzihou ${ }^{\mathrm{b}}$ \\ ${ }^{a}$ City College, City University of New York, Department of Chemical Engineering E Earth Engineering Center|CCNY, NY 10031, USA \\ ${ }^{\mathrm{b}}$ Université de Toulouse, Mines Albi, CNRS, Centre RAPSODEE, Campus Jarlard, F-81013 Albi Cedex 09, France
}

\begin{abstract}
A B S T R A C T
This research investigates the catalytic properties of char which was recovered directly from a biomass gasifier. Poplar wood was gasified in steam and $\mathrm{CO}_{2}$ environments in a fluidized bed reactor at temperatures ranging from 550 to $920^{\circ} \mathrm{C}$. Char was composed of $85 \%$ carbon with concentrations of $\mathrm{N}, \mathrm{H}$, and $\mathrm{S}$ between $0.3 \%$ and $3 \%$, depending on gasification conditions. The inorganics ( $\mathrm{Ca}, \mathrm{K}, \mathrm{Na}, \mathrm{P}, \mathrm{Si}, \mathrm{Mg}$ ) were quantified, revealing that $\mathrm{Ca}$ was present in the highest concentration $(0.5-1 \%)$, followed by $\mathrm{K}$, ranging from $0.1 \%$ to $0.8 \%$. The char had catalytic activity for decomposition of methane, which was used as a model molecule. The quantity of inorganics in the char was modified by acid washing in $16 \%$ aqueous $\mathrm{HCl}$, which removed $>95 \%$ of $\mathrm{Ca}, \mathrm{K}, \mathrm{P}$, and $\mathrm{Mg}$ from the char. This resulted in an $18 \%$ decrease in the quantity of methane reacted compared to the original char sample, demonstrating that inorganics, which only make up approximately $2 \%$ of the char, play a significant role in its catalytic activity for methane cracking reactions. In addition, carbon was found to play an important role in the catalytic activity of the char, both as a catalyst and a support on which the inorganics were dispersed. The activity of carbon free ash was approximately $90 \%$ lower than that of char, and deactivated to have no measurable activity after $45 \mathrm{~min}$ on stream, demonstrating the importance of carbon and dispersed inorganics for catalytic activity. When char was heated to $1000^{\circ} \mathrm{C}$ in $\mathrm{N}_{2}$, inorganics and oxygen migrated to the surface of the char, covering the carbon surface in a metal oxide layer. This decreased the catalytic activity by approximately $40 \%$. Acidic (e.g. carboxylic, lactones) and basic (e.g. carbonyl, pyrone) oxygen functional groups were identified on the char surface. However, acidic oxygen groups desorbed at reaction temperatures, so these groups likely do not participate in cracking reactions.
\end{abstract}

\section{Introduction}

In recent years, there has been growing interest in gasification as a method for energy recovery from solid fuels such as biomass, waste, sludge, or coal. The primary product of gasification is synthesis gas, which is a gas mixture that is rich in $\mathrm{CO}$ and $\mathrm{H}_{2}$. Synthesis gas can be used for production of fuels or chemicals (ex. diesel, methanol, ethanol), for steam generation via combustion boilers, or for electricity production in a gas turbine or fuel cell. One of the main issues with commercialization of gasification processes is the production of by-products such as tar and char. Tar is a mixture of hydrocarbons that condense at standard conditions, and must be either removed or reformed because it can cause problems in downstream equipment such as clogging or deposition

* Corresponding author at: 140th Street \& Convent Ave., New York, NY 10031, USA. Tel.: +1 2126506679 .

E-mail address: mcastaldi@ccny.cuny.edu (M.J. Castaldi).

${ }^{1}$ Current address: Gas Technology Institute (GTI), Des Plains, Il, USA. on surfaces. One way to address this is to catalytically reform tar, which increases the gaseous product yield. However, when using heterogeneous feed stocks such as agriculture or forestry residues, or municipal solid waste, catalysts are prone to deactivation. For example, sulfur or chlorine species which are present in the feedstock may poison catalytic sites or tars may crack and form coke on the catalyst. In this research, we are investigating utilization of char as a catalyst for tar reforming. This would be beneficial since the char is produced on-site, making it a cheap and available resource. In this research, the surface reactivity of char that was recovered directly from a biomass gasifier (with no modification) is studied. The contribution of inorganics, carbon, and oxygen groups to the catalytic activity of char is reported.

\subsection{Catalytic activity of char}

Char has been considered for a variety of applications such as energy recovery (via combustion), soil amendment, or as daily 
cover for landfills. This research investigates utilization of char in high value applications, such as catalysis. In recent years, char, or similar materials such as activated carbon (AC), have been reported to have catalytic activity for reforming or cracking of hydrocarbons [1-7]. When placed downstream of gasifiers, these materials have been shown to reduce tar production and increase syngas yield $[2,3,7]$. In addition, char has been used as a support for different metals ( $\mathrm{Ni}, \mathrm{Fe}$ ) and these catalysts have been used for reforming of biomass tars and tar surrogate compounds $[6,8]$.

Char properties vary with gasification conditions, so it is important to understand how these properties influence the catalytic activity of char. This enables one to identify which gasification processes produce char which is appropriate for use in catalytic applications. While char has similar properties to materials such as activated carbon (AC) and carbon molecular sieves (CMS), which have been studied extensively, there are some important differences. Since char is a by-product of gasification, its properties are dictated by the gasification conditions and the starting feedstock. The primary objective of a gasification process is to produce a high yield of syngas with a $\mathrm{CO} / \mathrm{H}_{2}$ ratio that is appropriate for a targeted end use. Therefore, the process conditions in which the char is produced are adjusted so the syngas yield is maximized. In contrast, in processes where the primary product is AC, the material is often chemically activated with potassium hydroxide, phosphoric acid, or steam which can affect both surface area and surface oxygen groups. In addition, AC is often de-ashed via acid washing whereas char is not. With growing interest in co-gasification of biomass with coal or municipal solid waste, which contain higher concentrations of ash species, it is important to consider the role of ash species in the catalytic activity of the char. Furthermore the oxygen functional groups may affect the catalytic activity and are also studied here.

In addition to surface chemistry, catalytic activity is affected by char morphology. In a previous publication, we reported the influence of char surface area and porosity on its catalytic activity [9]. Higher gasification temperatures (up to $920^{\circ} \mathrm{C}$ ) produced char with higher surface area. For example, increasing the gasification temperature from 750 to $920^{\circ} \mathrm{C}$ in a $\mathrm{CO}_{2} / \mathrm{N}_{2}$ environment resulted in an increase in surface area from 435 to $687 \mathrm{~m}^{2} \mathrm{~g}^{-1}$. For all surface area measurements, the correlation coefficient was greater than 0.999. Preliminary data showed that char with higher surface area had higher catalytic activity. The goal of the research presented in this paper is to further understand the contributions of inorganics, carbon, and oxygen groups to the catalytic activity of char that was recovered directly from a biomass gasification process.

\subsection{Inorganics in biomass char}

Biomass is primarily composed of carbon, oxygen, and hydrogen in molar ratios of approximately 6/4/10. Importantly, it also contains inorganics which have been demonstrated in the literature to impact various reactions. The inorganic fraction of biomass is typically composed primarily of alkali and alkaline earth metallic species (AAEM), such as $\mathrm{Ca}, \mathrm{Na}, \mathrm{K}, \mathrm{Mg}$, but also contains $\mathrm{Si}$ and $\mathrm{P}$, and transition metals such as $\mathrm{Fe}, \mathrm{Al}$, and $\mathrm{Mn}$. While the concentrations of these elements vary depending on the species of biomass or its growing conditions, they are found in many types of biomass. Dupont et al. characterized the inorganic elements in 21 different types of wood, including spruce, poplar, oak, pine, and beech, and found significant differences in concentrations, yet commonality of species [10]. For example, ash content varied from $0.5 \%$ to $4.3 \%$, calcium varied from $0.086 \%$ to $1.6 \%$ by mass (based on dry biomass), and potassium concentration varied from 0.011 to $0.18 \%$ by mass (based on dry biomass). Yip et al. determined that the ash of mallee biomass contained $>85 \%$ alkali and alkaline earth metallic species (AAEM) [11], and that $80-90 \%$ of these inorganics remained in the solid residue following steam gasification at $750{ }^{\circ} \mathrm{C}$. Others have observed volatilization of some of the inorganic species during gasification [12,13]. However, in general at least some fraction of the inorganics remain in the solid residue after gasification. Therefore, char from biomass gasification has an inorganic fraction which will remain despite the starting feedstock and operating conditions that will influence its catalytic activity.

\subsection{Catalytic activity of inorganic elements in gasification reactions}

Gasification involves many complex reactions and significant efforts have been made to understand reaction mechanisms. It has been shown that inorganics participate in catalyzing gasification reactions. For example, Yip et al. gasified mallee biomass and observed lower reactivity when the feedstock had been acid washed prior to gasification [11]. Marquez-Montesinos et al. studied the role of inorganics on gasification of grapefruit skin char and found that the presence of inorganics improves the reaction kinetics [14]. Dupont et al. correlated the rate of gasification to the ratio of potassium to silicon in the biomass, and concluded that potassium has a catalytic effect and silicon an inhibitory effect [10]. Habibi et al. also observed inhibitory effects of silicon during co-gasification of potassium rich switchgrass with high ash sub-bituminous coal. They found that the potassium can be rendered inactive when potassium aluminosilicate is formed [15]. Since inorganics have been correlated to gasification kinetics it is important to more quantitatively understand how they impact the catalytic activity of char, specifically for hydrocarbon decomposition reactions. Tar reforming with steam showed $\mathrm{Ni}$-char catalysts performing better than $\mathrm{Fe}$-char. The authors chose to further study the Fe-char and obtained an interesting finding. The syngas produced during the reforming maintained Fe in the reduced state comparable to pre-reduction which gave the catalyst its activity [16]. Fe-char catalyst from coal showed stable activity for up to 50 min time on stream for the steam reforming of mallee biomass tar. It was also found that the activity was affected by the char structure and the properties of the Fe speciation [17].

\subsection{Role of oxygen groups in catalytic activity of carbon materials}

It is well known that acid groups play a role in many types of catalytic reactions, such as cracking, isomerization, and polymerization [18]. Acidic or basic sites are formed on a char surface when oxygen reacts with defect sites on the surface, forming functional groups. Some examples of the functional groups detected are carboxylic acids, lactones, or phenols (acidic) and pyrones or chromenes (basic). Acidic surface groups have been studied more extensively than basic sites, and it is understood which types of surface functionalities give rise to surface acidity [19,20]. In general, acidic sites are formed when a surface is heated in an oxidizing environment and basic groups are formed when an oxidized surface is reduced by heating in an inert environment [20].

The surface functional groups influence the adsorption of molecules to the char surface. For example, oxygen sites enhance the adsorption of polar molecules, such as water which is present in many systems. Lee et al. studied the adsorption of water vapor on chemically activated carbons derived from coal and wood and found that in cases where the relative pressure of water was low $\left(P / P_{0}<0.4\right)$, the density of oxygen groups on the carbon surface was the most important factor that influenced water adsorption [21]. When char is used as a catalyst, reactants must adsorb to the surface, react, and products must desorb. However, it is not desirable for molecules that do not participate in the catalytic reaction to adsorb to the surface as this can hinder access to catalytic 
sites. Therefore, surface properties and the adsorption of reactant or other spectator molecules should be understood since they affect the catalytic activity of the char. While research has been done on the influence of oxygen groups on adsorption of various molecules such as water or aromatics to carbon surfaces, it is typically done for systems operating at low temperatures or in aqueous environments. The catalytic reactions studied here take place at high temperatures (above $700{ }^{\circ} \mathrm{C}$ ) and at the gas/solid interface, as discussed above. This is the first study to our knowledge that investigates the influence of oxygen functional groups on the char surface on its catalytic activity for hydrocarbon decomposition reactions.

While catalytic activity of char has been demonstrated, the contribution of char properties to its catalytic activity is not well understood. Since char is a by-product of gasification, its properties depend on gasification conditions and starting feedstock. The properties which have been shown to affect its catalytic activity are its morphology (surface area and porosity), and its composition. Since the influence of morphology on catalytic activity of char has been presented in a previous publication [9] this paper will focus on the influence of char composition on its catalytic activity, specifically the role of inorganics and acidic oxygen groups which are present. The bulk properties such as carbon, hydrogen, nitrogen, sulfur and inorganic (ash) species are analyzed, as well as the role of concentration and distribution of inorganics. In addition, the influence of oxygen functional groups on the catalytic activity of char is also quantified. In all cases, unless otherwise indicated, the char morphology remained constant in experiments which compared char with different compositions.

\section{Experimental}

\subsection{Char production}

The char used in the experiments presented in this paper was from gasification of poplar wood in an updraft fluidized bed reactor, as shown in Fig. 1. The poplar wood chips were $\sim 4 \mathrm{~mm} \times 4 \mathrm{~mm} \times 1 \mathrm{~mm}$. The gasification medium was either $\mathrm{CO}_{2}$ or $\mathrm{H}_{2} \mathrm{O}$ at concentrations of $10-90 \%$, with the balance gas being

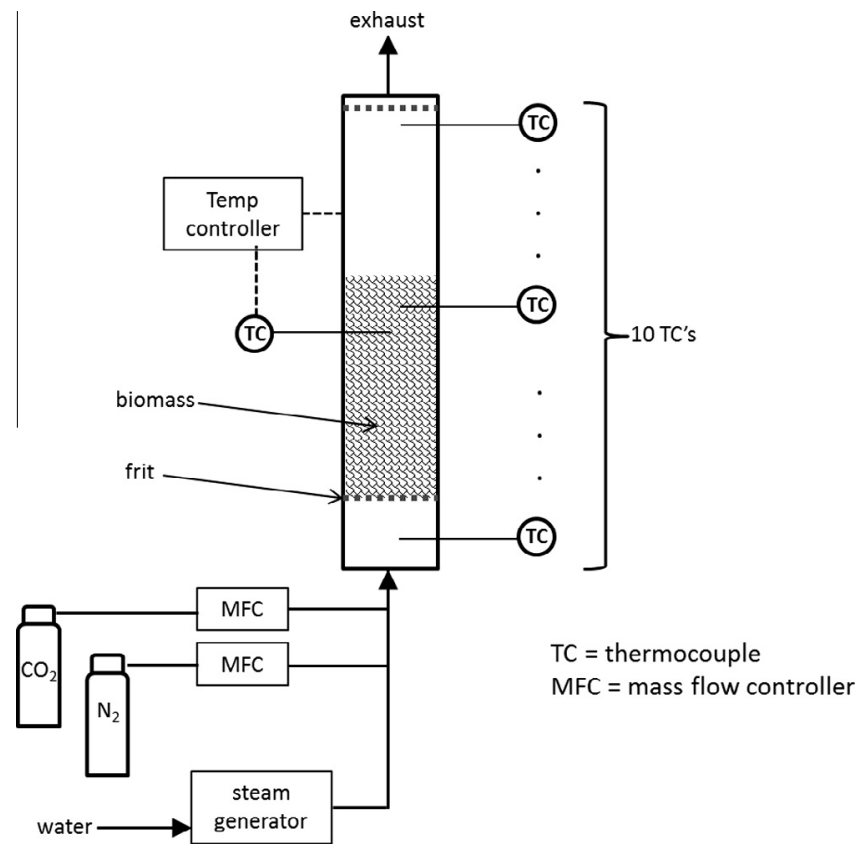

Fig. 1. Diagram of fluidized bed reactor used for gasification of biomass. Biomass becomes fluidized when flow is introduced.
$\mathrm{N}_{2}$. Gases were supplied by Air Liquide; $\mathrm{N}_{2}$ was $99.95 \%$ and $\mathrm{CO}_{2}$ was $99.995 \%$ purity. TGA/DSC testing that was done with nitrogen of the same quality showed no significant heat flux at high temperatures, indicating that there was no measurable oxygen impurity present in the gas. The total gas flow rate was 400 SLPM kg-1 of biomass (SLPM is standard liters per minute). The reactor was stainless steel with an internal diameter of $6.1 \mathrm{~cm}$ and a height of $59.9 \mathrm{~cm}$. The reactor temperature was controlled with a Eurotherm temperature controller which was connected to a thermocouple placed in the center (vertically and radially) of the reactor. The biomass was loaded into the reactor prior to each experiment and the char was collected after the experiment. The reactive gas mixture $\left(\mathrm{H}_{2} \mathrm{O} / \mathrm{N}_{2}\right.$ or $\left.\mathrm{CO}_{2} / \mathrm{N}_{2}\right)$ was introduced into the system. The reactor temperature was then increased at $20^{\circ} \mathrm{C} \mathrm{m^{-1 }}$ in the reaction environment to a predetermined set point, which ranged from 550 to $920^{\circ} \mathrm{C}$. After each experiment, the reactor was cooled down to room temperature under nitrogen. Therefore, no measurable reactions would have taken place on the char surface with room air, since the char was only exposed to air at room temperature, where kinetics of such reactions would be immeasurably slow. Gasification was done at different conditions to assess the property variations of char produced. The char samples will be referred to throughout this paper using names indicated in Table 1, which describes the gasification environment, the maximum reactor temperature, and the time that the reactor remained at that temperature. For example, $\mathrm{CO}_{2}-920-30$ refers to char from gasification in a $\mathrm{CO}_{2}$ environment where the biomass was heated to $920^{\circ} \mathrm{C}$ and held at that temperature for $30 \mathrm{~min}$.

\subsection{Char characterization}

The BET surface area of each char sample was measured using multi point BET Analyzer (Micromeretics, Gemeni) and is reported in Table 1. The structure and chemical composition of the char was analyzed in an Environmental Scanning Electron Microscope (ESEM, FEI XL30) with energy dispersive X-ray spectroscopy (EDS). The concentrations of carbon, hydrogen, nitrogen, and sulfur were measured with a ThermoQuest CHNS Elemental Analyzer.

\subsection{Removal of inorganics}

Inorganics were removed from the char by treating it in a solution of $16 \%$ hydrochloric acid (Aeros organics CAS 7647-01-0, diluted with water which was purified using a Millipore Simplicity system with a SIMPAKOR1 cartridge). Since Si has been shown to have inhibitory effects during gasification and transition metals were present in the char in very low concentrations, the goal of the de-ashing process was to reduce the concentration of AAEM species and phosphorus. The procedure applied was similar to reported acid washing techniques for de-ashing char [11,14,22]. Char was immersed in the acid solution at room temperature for $24 \mathrm{~h}$. Following acid treatment the char was rinsed approximately 25 times with purified water and then dried at $120^{\circ} \mathrm{C}$ to ensure that all of the acid had been removed. A sample of the treated char was then fully dissolved in an acid solution and the concentrations of

Table 1

Reaction conditions and surface areas of different char samples.

\begin{tabular}{lllll}
\hline Sample name & $\begin{array}{l}\text { Reaction } \\
\text { atmosphere }\end{array}$ & $\begin{array}{l}\text { Maximum } \\
\text { temperature } \\
\left({ }^{\circ} \mathrm{C}\right)\end{array}$ & $\begin{array}{l}\text { Time at } \\
T_{\max }(\mathrm{min})\end{array}$ & $\begin{array}{l}\text { Surface } \\
\text { area }\left(\mathrm{m}^{2} \mathrm{~g}^{-1}\right)\end{array}$ \\
\hline $\mathrm{CO}_{2}-920-30$ & $10 \% \mathrm{CO}_{2} / 90 \% \mathrm{~N}_{2}$ & 920 & 30 & 687 \\
$\mathrm{CO}_{2}-750-30$ & $10 \% \mathrm{CO}_{2} / 90 \% \mathrm{~N}_{2}$ & 750 & 30 & 435 \\
$\mathrm{H}_{2} \mathrm{O}-750-60$ & $90 \% \mathrm{H}_{2} \mathrm{O} / 10 \% \mathrm{~N}_{2}$ & 750 & 60 & 621 \\
$\mathrm{H}_{2} \mathrm{O}-750-30$ & $90 \% \mathrm{H}_{2} \mathrm{O} / 10 \% \mathrm{~N}_{2}$ & 750 & 30 & 429 \\
\hline
\end{tabular}


inorganics were measured via ICP to determine the concentration of inorganics in the treated char. For this test, the char was dissolved in a mixture of nitric and hydrochloric acids and was heated to help with dissolution of the char. For quantification of silicon, hydrofluoric acid was used. ICP testing and sample preparation was done by a certified lab (SGS laboratories, in France). The surface area and pore volume of the char were measured before and after acid washing treatments which confirmed that there were no significant changes in char morphology from the acid treatment. The catalytic activity of the char was compared to that of the acid washed char according to the procedure discussed in Section 2.4.

\subsection{Catalytic activity testing}

The catalytic activity of the char was tested via the methane decomposition reaction. This reaction was chosen because it provides insight on the char's ability to activate $\mathrm{C}-\mathrm{H}$ bonds and produces few reaction products compared to decomposition of larger molecules, such as toluene, which more closely resemble gasification tars. The main products from methane decomposition are solid carbon and $\mathrm{H}_{2}$, which are easily and reliably measured, allowing for quantification of reaction extent. It is also possible that $\mathrm{CH}_{x}$ compounds form on the char surface, according to Eq. (1).

$\mathrm{CH}_{4} \rightarrow \mathrm{CH}_{x}+y \mathrm{H}_{2}$ where $0<x<3$ and $y=2-0.5 x$

Catalytic testing of the char was done in a flow through reactor and in a thermo gravimetric analyzer (TGA). The flow through reactor was able to accept a larger quantity of char than the TGA and provided a more realistic reactor configuration. TGA tests enabled precise temperature measurement and high frequency measurement of the mass change. Data was recorded every $2 \mathrm{~s}$ during tests.

(i) Flow through reactor tests $-\mathrm{CH}_{4}$ decomposition: A quartz flow through packed bed reactor was used for catalyst testing as shown in Fig. 2. Gases were supplied by Tech Air and were ultra high purity (UHP) grade. The mass of char for each test was $0.02 \mathrm{~g}$. The system was heated to a target temperature $\left(700,750\right.$, or $\left.850^{\circ} \mathrm{C}\right)$ in $\mathrm{N}_{2}$ and then a mixture of $15 \% \mathrm{CH}_{4}$ (balance $\mathrm{N}_{2}$ ) was introduced. In some tests $\mathrm{CH}_{4}$ composition varied and this is indicated in the text when this is the case. The flow rate of the gas mixture was approximately $50 \mathrm{ml} \mathrm{min}{ }^{-1}$. The $\mathrm{H}_{2}$ concentration in the effluent was measured on line with an Inficon 3000 micro gas chromatograph.

(ii) Thermo gravimetric analyzer test $-\mathrm{CH}_{4}$ decomposition: A Netzsch STA 409PC TGA was used for catalytic testing. The

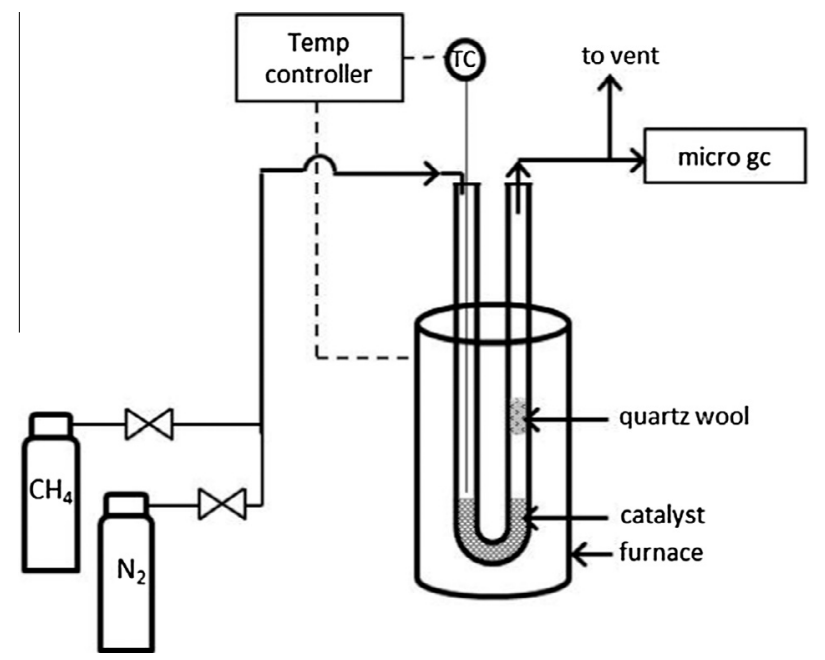

Fig. 2. Diagram of reactor setup for flow through catalyst testing. $\mathrm{TC}=$ thermocouple $(\mathrm{K}$ type $)$.
TGA crucible was alumina with an inner diameter of $6.5 \mathrm{~mm}$ and a height of $13 \mathrm{~mm}$. For each test approximately $5 \mathrm{mg}$ of char was placed in the crucible. The char occupied only a thin layer $(\sim 3 \mathrm{~mm})$ on the bottom of the crucible to mitigate bed depth and transport effects. The char was taken directly from the gasifier therefore the particle size was slightly variable but was generally in the range of $1-3 \mathrm{~mm}$ for each dimension (particles were roughly rectangular). Due to the large particle size it is not likely that there were inter particle mass transfer limitations that would have affected reaction kinetics. The test procedure was as follows. A mixture of $30 \% \mathrm{CH}_{4}$ (balance $\mathrm{N}_{2}$ ) was introduced (Tech Air, UHP). Char was heated to $150{ }^{\circ} \mathrm{C}$ at $7{ }^{\circ} \mathrm{C} \mathrm{min}^{-1}$ and held for 20 min to allow for drying of the sample. During this time a stable mass was achieved, which confirmed drying was complete. The temperature was subsequently increased to $900{ }^{\circ} \mathrm{C}$ at $7^{\circ} \mathrm{C} \mathrm{min}^{-1}$. The methane decomposition reaction involves the formation of solid carbon or radical $\mathrm{CH}_{x}$ species terminated by surface attachment on the char, therefore the sample mass and hydrogen evolution were considered to be representative of reaction taking place.

\subsection{Temperature programmed desorption}

Oxygen functional groups on the char were identified via temperature programmed desorption (TPD), which involves heating the char at a constant rate in an inert atmosphere, such as nitrogen or helium [23-25]. Each type of functional group desorbs at a specific temperature as either $\mathrm{CO}$ or $\mathrm{CO}_{2}$, so by measuring the gases evolved, the functional groups can be identified. Szymanski et al. have provided a review of the gas evolution profiles (temperature and gas evolved) that are associated with different types of surface groups [25]. TPD was done using a Quantachrome ChemBET Pulsar instrument and the char was heated in $\mathrm{N}_{2}$ at $10^{\circ} \mathrm{C} \mathrm{min}^{-1}$ to $1000^{\circ} \mathrm{C}$ and held at that temperature for $15 \mathrm{~min}$. An Inficon 3000 micro GC was coupled to the system for gas analysis to distinguish the production of $\mathrm{CO}$ and $\mathrm{CO}_{2}$. It should be noted that in heating the char to temperatures above the temperature at which the char was formed (for example, performing TPD up to $1000^{\circ} \mathrm{C}$ on char from a gasification process that was done at $750{ }^{\circ} \mathrm{C}$ ) the properties of the char surface may change. However, the evolution of $\mathrm{CO}$ and $\mathrm{CO}_{2}$ provides information on the groups that were present on the surface of the original char sample.

\subsection{Oxygenation of char surface}

To understand the role of oxygen in the catalytic activity of char, the surface was oxygenated and the activity of the original char was compared to the oxygenated char. The char was oxygenated via treatment with nitric acid, which was obtained from Fisher (certified ACS plus, catalog No. A200-212). $80 \mathrm{mg}$ of char sample $\mathrm{CO}_{2}-920-30$ was immersed in $50 \mathrm{~mL}$ of $16 \%$ nitric acid at $80^{\circ} \mathrm{C}$ for $2 \mathrm{~h}$. After allowing the sample to cool to room temperature, the sample was rinsed approximately 25 times with distilled water. Char samples were dried with a vacuum pump/filter at room temperature. ICP was done on the acid mixture following the char treatment which confirmed that no inorganics had leached out of the char into the acid solution, as expected, since stronger acids such as $\mathrm{HCl}$ or $\mathrm{HF}$ are typically used to remove inorganics from char. Temperature programmed desorption (TPD) was used to verify that the amount of surface functionalities on the acid-treated char was higher than the raw char. The surface area was measured before and after oxygenation of the char sample using a Quantachrome NOVA surface area analyzer and a decrease in surface area was observed. It has been reported in the literature that when oxygen groups are added to high surface area carbon 
materials, there is a reduction in surface area [25-27]. This has been attributed to bulky $\mathrm{COOH}$ groups that adsorb at the entrance of the micro pores, blocking the access of $\mathrm{N}_{2}$ or other molecules to the micro pores, which are used to measure the surface area. Therefore, surface area measurements were also used to confirm that the oxygen groups had been added to the surface.

\section{Results and discussion}

\subsection{Char composition}

The concentrations of carbon, hydrogen, nitrogen, and sulfur in the char were measured. The results are shown in Fig. 3 for three samples that were made in a gasification environment of $10 \%$ $\mathrm{CO}_{2}$ (balance nitrogen) at 550, 750 , and $920^{\circ} \mathrm{C}$. As the gasification temperature increased the quantity of char decreased due to a higher conversion to gas phase products. The mass of char recovered was $16.2 \%, 15.4 \%$, and $11.8 \%$ of the initial biomass for gasification done at 550,750 , and $920^{\circ} \mathrm{C}$, respectively. The concentration of carbon was approximately $85 \%$ for all char samples. The nitrogen concentration was lower for the sample made at $550{ }^{\circ} \mathrm{C}$, indicating that nitrogen is less volatile than the other species, and is more likely to be retained in the char (as more of the char is gasified, nitrogen represents a larger fraction of the solid residue). There were no significant differences in sulfur concentrations among the different char samples. Hydrogen concentration decreased as temperature increased, suggesting that hydrogen is more easily removed from the biomass structure and at higher temperatures is more likely to be released as $\mathrm{H}_{2}$ or as $\mathrm{CH}_{x}$ compounds.

The inorganic compounds were measured via ICP and results are shown in Table 2 . These species comprise approximately $2 \%$ of the char. Calcium was present in the highest concentration, followed by potassium, as expected. The lowest gasification temperature $\left(500{ }^{\circ} \mathrm{C}\right)$ has the lowest carbon conversion, therefore concentrations of inorganics are lowest in this char due to the high

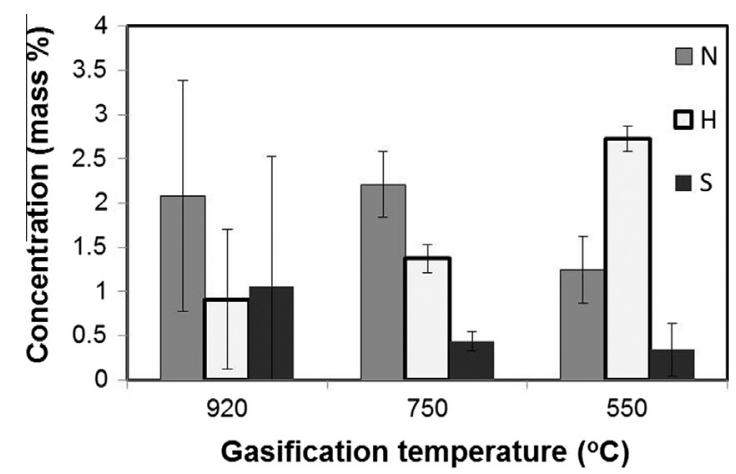

Fig. 3. Concentrations of $\mathrm{N}, \mathrm{H}$, and $\mathrm{S}$ in char from gasification with $10 \% \mathrm{CO}_{2}$ (balance $\mathrm{N}_{2}$ ) at various temperatures.

\section{Table 2}

Concentrations of inorganic elements in char from gasification in $10 \% \mathrm{CO}_{2}$ (balance $\mathrm{N}_{2}$ ) at different reaction temperatures. Units are ppmM ( $\left.\mathrm{mg} \mathrm{kg}^{-1} \mathrm{char}\right)$. Concentrations of $\mathrm{Fe}, \mathrm{Mn}$, and $\mathrm{Al}$ were below the detection limit of $50 \mathrm{ppm}$.

\begin{tabular}{lllll}
\hline & Poplar wood & Char $\left(920^{\circ} \mathrm{C}\right)$ & Char $\left(750^{\circ} \mathrm{C}\right)$ & Char $\left(550^{\circ} \mathrm{C}\right)$ \\
\hline $\mathrm{Ca}$ & 5200 & 8300 & 10,900 & 7800 \\
$\mathrm{~K}$ & 1200 & 7900 & 7200 & 7000 \\
$\mathrm{Na}$ & $<50$ & 66 & 64 & 67 \\
$\mathrm{P}$ & 113 & 571 & 1050 & 710 \\
$\mathrm{Si}$ & $<50$ & 70 & 63 & $<50$ \\
$\mathrm{Mg}$ & 340 & 1200 & 1200 & 985 \\
Total (wt\%) & 0.69 & 1.81 & 2.05 & 1.59 \\
\hline
\end{tabular}

quantities of carbon and oxygen in the residue. At higher temperatures, as carbon conversion increases, inorganics make up a higher fraction of the char. The concentration of calcium is lower when the gasification temperature was $920^{\circ} \mathrm{C}$ compared to $750{ }^{\circ} \mathrm{C}$. This is likely due to volatilization of these species at high temperatures. Volatilization of AAEM species during pyrolysis and gasification of coal or biomass has been observed by others $[13,28]$. The proposed mechanism for devolatilization of AAEM species is that they exit the char as carboxylates. Phosphorus likely volatilizes in the form of phosphorus oxides. Volatilization of phosphorus from sewage sludge has been studied and Bourgel et al. determined that $\left(\mathrm{P}_{2} \mathrm{O}_{3}\right)_{2}$ would be present as a gaseous species at temperatures above $700{ }^{\circ} \mathrm{C}$ [29]. The mechanism for volatilization is likely different in wood char versus sewage sludge and therefore understanding the mechanism of volatilization of inorganic compounds from wood is a subject for future study. The oxygen concentration is determined by difference and makes up $8-10 \%$ of the char. EDS measurements, which give a local concentration measurement, confirmed that on the surface the oxygen concentration was in this range. The rest of this paper will focus on catalytic activity of char from gasification processes at 750 and $920^{\circ} \mathrm{C}$. This is because these char samples have significantly higher surface area, and consequently higher catalytic activity compared to char from gasification at $550^{\circ} \mathrm{C}$. In addition, the higher temperature processes represent more commonly used gasification conditions.

\subsection{Influence of inorganics on catalytic activity}

Many ash-free carbon materials such as activated carbon and carbon molecular sieves have been extensively studied and it is well known that the carbon material has some catalytic activity due to its high surface area. In this research, the goal is to evaluate the catalytic activity of char that is recovered directly from a gasifier without further modification of the char. In addition, with recent interest in co-gasification of biomass with coal or waste, the presence of inorganic species in char may become more important since coal and MSW often have higher concentrations of inorganics compared to biomass.

The influence of inorganic species (AAEM species and phosphorus) on the catalytic activity of char can be understood by comparing the activity of two char samples with different concentrations of inorganics. To do a direct comparison, char samples with similar surface areas but different concentrations of inorganics must be compared. However, the three char samples which are shown in Table 2 all have different surface areas. Therefore, the concentration of inorganics in one char sample $\left(\mathrm{CO}_{2}-920-30\right)$ was reduced by an acid treatment described in Section 2.3, and the catalytic activity of the de-ashed char was compared to that of the raw char. The surface area and porosity of the samples were measured after the acid treatments to verify that there were no significant changes in morphology from these treatments. ICP measurements determined that the acid washing treatment removed $>95 \%$ of $\mathrm{Ca}, \mathrm{P}, \mathrm{K}$, and $\mathrm{Mg}$.

The catalysts were tested for methane decomposition using a TGA according to the procedure described in Section 2.4. TGA data from one of these tests (with acid washed char) is shown in Fig. 4. Here, water loss is visible at $100-150{ }^{\circ} \mathrm{C}$, followed by some mass loss between 150 and $650{ }^{\circ} \mathrm{C}$. This is due to desorption of functional groups on the surface, and possibly other volatiles. The inflection point on the graph indicates light off, or initiation of catalytic decomposition of methane, which produces carbon on the surface. Fig. 5, shows the catalytic activity, as $\mathrm{mmol}$ of $\mathrm{H}_{2}$ produced per $g$ of char. The mass gain is representative of the cumulative amount of methane reacted, since one mole of carbon is deposited on the char surface for every mole of methane that reacts. The 


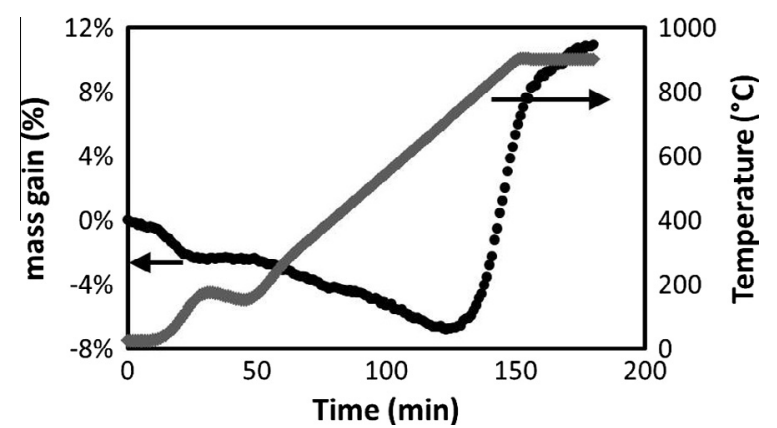

Fig. 4. Mass gain from acid washed char under $\mathrm{CH}_{4} / \mathrm{N}_{2}$ mixture. Mass gain is a result of catalytic cracking of methane, which forms carbon on the char surface.

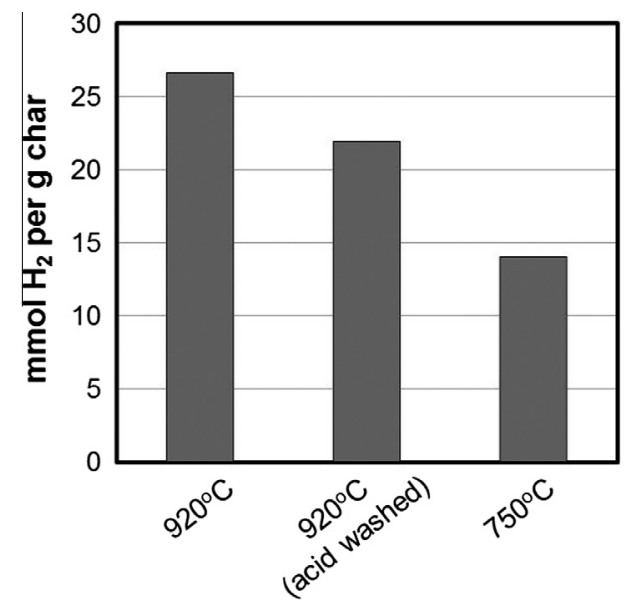

Fig. 5. Catalytic activity of char. Abscissa label describes temperature of the gasification process from which char was recovered. Acid washing of the char resulted in removal of alkali and alkaline earth metals (AAEM), which resulted in lower catalytic activity. Char from gasification at $750{ }^{\circ} \mathrm{C}$ had lower catalytic activity due to lower surface area of the char. Error on these measurements was $9 \%$.

sample that was treated in acid solution exhibited a lower catalytic activity; final mass gain was reduced from $16 \%$ to $13 \%$. The reaction rate was reduced by approximately $16 \%$ when the temperature was below $850{ }^{\circ} \mathrm{C}$. For temperatures above $850{ }^{\circ} \mathrm{C}$, the reaction rate was reduced by approximately $27 \%$. This indicates that, while these components make up less than $2 \%$ of the char by mass, the removal of such compounds could result in a decrease in catalytic activity of up to $27 \%$. The presence of alkali and alkaline elements contributes to the catalytic activity of the char. These elements have been shown to take part in catalyzing gasification reactions $[10,14]$. Here, we show that they also take part in cracking reactions; therefore, the inorganics may play a role in cracking of tars inside the gasifier, which would improve the syngas yield. This indicates that biomass or waste with higher ash content may be beneficial for gasification. Moreover, some of the alkali and alkaline elements which are present in biomass have been used as catalysts for tar cracking. The most common AAEM based catalysts are mineral oxides or carbonates made from calcium or magnesium [30-32]. This is aligned with the results presented here which demonstrate the catalytic activity of these elements in char.

Fig. 5 also shows the catalytic activity of char from a gasification process that was done at $750^{\circ} \mathrm{C}$. According to Table 2, char made at $920^{\circ} \mathrm{C}$ has a total concentration of inorganics of $1.8 \%$ and char made at $750^{\circ} \mathrm{C}$ has an inorganics concentration of $2.0 \%$. However, the surface area of char made at $750{ }^{\circ} \mathrm{C}$ is $63 \%$ of the char made at $920^{\circ} \mathrm{C}$ (i.e. 429 compared to $687 \mathrm{~m}^{2} \mathrm{~g}^{-1}$ ) which explains the significant difference in catalytic activity. It is known that for
AC the surface area is highly dependent on temperature and impacts the catalytic activity. Here, we show that both the surface area and the inorganics influence the catalytic activity. While inorganics make up only $2 \%$ of the char, an $18 \%$ reduction in the amount of methane reacted is observed when inorganics are removed therefore they serve to enhance the catalytic activity of the char.

Given that the inorganics clearly play an important role in the catalytic activity of the char, we investigated whether ash, composed of only inorganics would have a higher catalytic activity than char. Utilization of ash (ie no carbon) as a catalyst could be beneficial, especially since char has a heating value. So, for example, char could be burned for process heat, and the ash subsequently used as a catalyst. Exposure of char to air could result in a change in composition (less carbon) as well as a change in oxidation state of the metals. Combustion processes typically produce a solid residue with a carbon content in the range of $0.1-1 \%$ compared to char studied here, which has a carbon content of $85 \%$. Alternatively, gasification processes could use air rather than $\mathrm{CO}_{2}$ or steam which may result in higher carbon conversion, producing a solid residue with low concentrations of carbon.

Char was exposed to air at $700{ }^{\circ} \mathrm{C}$ for $30 \mathrm{~min}$, which resulted in removal of all of the carbon via combustion. This produced a white ash, which was composed of the metals and minerals which were present in the original char sample. The catalytic activity of the ash was compared to that of the char according to the procedure described in Section 2.4. Hydrogen production from these tests is shown in Fig. 6. The char had much higher activity than the ash, as demonstrated by the higher $\mathrm{H}_{2}$ concentration. This indicates that the presence of carbon improves the catalytic activity of the char. The most likely reasons for this are: (i) carbon itself has catalytic activity (ii) interactions between the carbon and inorganic species contribute to catalytic activity of the char (iii) carbon provides a high surface area support on which inorganics are dispersed. The fact that the de-ashed char samples had catalytic activity indicates that the carbon itself has catalytic activity. Carbon based catalysts have been used for methane decomposition, and this has been reported in the literature [33]. For example, Serrano et al. used CMK carbons (ordered mesoporous carbons), carbon black, and graphite, which had metal concentrations below $0.005 \mathrm{wt} \%$ for methane cracking, which demonstrates that the carbon itself has some catalytic activity [34]. Metal-support interactions have been observed and reported in the literature for carbon supported metal catalysts. For example, Hsu et al. used a carbon supported iron or copper catalysts for NO reduction with $\mathrm{NH}_{3}$ [35]. They attribute the activity to the redox properties of the carbon-metal complexes, where the metal was oxidized by NO, and then reduced by carbon. Illán-Gómez et al. also used char supported metal catalysts for $\mathrm{NO}_{x}$ reduction and studied the redox

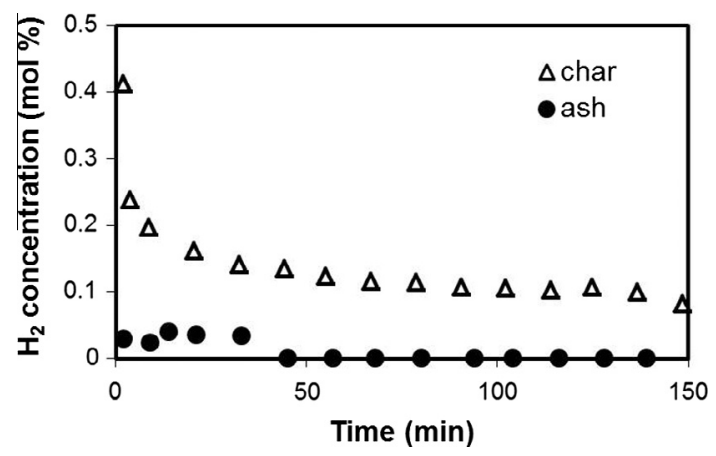

Fig. 6. Hydrogen production from decomposition of methane. Char has higher catalytic activity than ash, indicating that the presence of carbon improves catalytic activity. 
properties of the different complexes. They found the activity to be related to the ability of the metal to be oxidized by NO and reduced by carbon [36]. The role of carbon as a support for the inorganics is also important. The influence of dispersion on catalytic activity of the char is discussed in the next section.

\subsection{Influence of dispersion of inorganics on catalytic activity of char}

Supported catalyst materials are used most efficiently when they are highly dispersed, which increases the available catalytic surface area. Various techniques have been developed to achieve high catalyst dispersion on a support, for example incipient wetness impregnation, adsorption, or precipitation methods [18]. Since dispersion is an important catalyst property, and the inorganics in the char are catalytic, it is relevant to understand the dispersion of inorganics on the char surface. This property is affected by the reaction environment. For example, it has been shown that agglomeration of inorganics takes place during gasification in $\mathrm{H}_{2} \mathrm{O}$ at $1000{ }^{\circ} \mathrm{C}$ but this is lower during gasification in a $\mathrm{CO}_{2}$ environment [9]. However, even if the inorganics on the char are highly dispersed, agglomeration could take place when char is used as a catalyst for high temperature reactions.

ICP measurements (reported in Section 3.1) confirmed the presence of inorganics in the bulk char and EDS measurements indicated that inorganics are present near the surface of the char (EDS measured to a depth of $1 \mu \mathrm{m}$ ). The organic compounds were

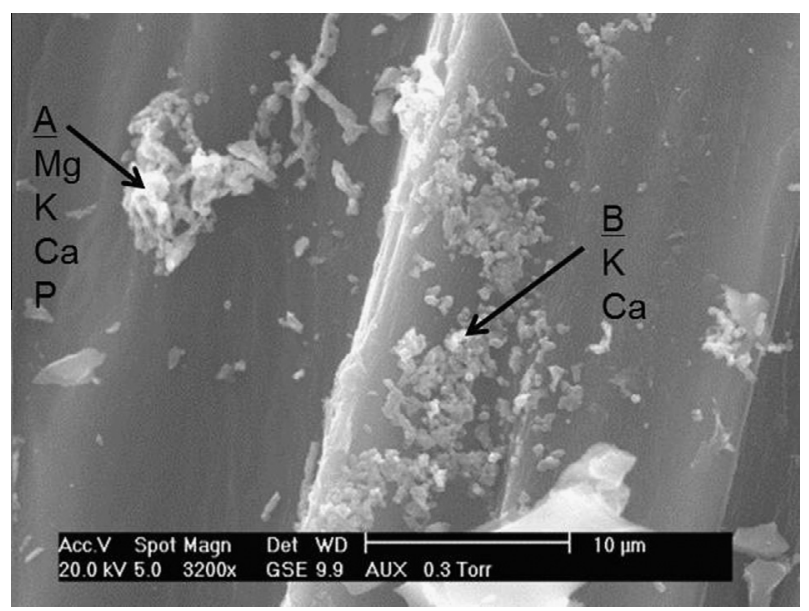

Fig. 7. ESEM image of char from gasification in steam at $750{ }^{\circ} \mathrm{C}$ (with a solids residence time of $30 \mathrm{~min}$ at $T_{\max }$ ). Inorganics are present in visible clusters, as shown above. Some elements, such as $\mathrm{Ca}$ and $\mathrm{K}$ are detected by EDS on the surface in particles that are too small to be observed visually. Concentrations (as weight\%) at point $\mathrm{A}$ are: $\mathrm{Mg} 0.4 \%, \mathrm{~K} 1.7 \%, \mathrm{P} 0.6 \%, \mathrm{Ca} 8.3 \%, \mathrm{C} 75.9 \%, \mathrm{O} 13.3 \%$. Concentrations (as weight \%) at point $\mathrm{B}$ are: $\mathrm{K} 3.2 \%$, Ca $2.8 \%$, C $86.0 \%$, $\mathrm{O} 8.0 \%$. found to be dispersed on the char surface. Fig. 7 shows an ESEM image of char where particles of inorganics such as $\mathrm{Ca}, \mathrm{Mg}, \mathrm{P}$, and $\mathrm{K}$ are visible at concentrations ranging from 0.4 to 8.3 weight percent. The particle size is in the range of $0.4-0.8 \mu \mathrm{m}$. Ca and $\mathrm{K}$ were also detected throughout the char, even when particles such as those seen in Fig. 7 were not visible, which signifies that the particle size must be smaller than $0.1 \mu \mathrm{m}$ (due to SEM sensitivity), and are highly dispersed. In addition, XRD did not detect many of the inorganic compounds that were detected by the other techniques. This is due to the resolution of XRD detecting only the concentration higher than $1 \%$.

The dispersion of inorganics on the char surface was altered by heating the sample to $1000^{\circ} \mathrm{C}$ in $\mathrm{N}_{2}$ which caused agglomeration and can be used as a comparison of the ash only where the surface area of the minerals is similar. This is discussed in detail in another publication, which shows ESEM images of particle agglomeration [9]. An example is shown in Fig. 8. Fig. 8A shows an ESEM image of char from gasification in steam. Fig. 8B shows the same char sample after being heated to $1000{ }^{\circ} \mathrm{C}$ in $\mathrm{N}_{2}$. The agglomeration of inorganics is clearly visible on the char surface, where the lighter color indicates the presence of metal oxides. In addition to agglomeration of inorganics, it is possible that the state of the inorganics is changed due to the migration of both oxygen and metals to the surface of the char. This layer covers part of the carbon which is exposed, reducing the number of carbon-metal sites. Cazorla-Amoros et al. studied how dispersion of calcium on high surface area carbon impacts its reactivity and quantified the impact of temperature on dispersion [37]. They loaded calcium onto carbon supports and measured the dispersion of calcium after various pyrolysis and gasification treatments. They compared the calcium dispersion for two samples: one sample had been pyrolyzed at $750{ }^{\circ} \mathrm{C}$ at $20^{\circ} \mathrm{C} \mathrm{min}^{-1}$ and the other sample was exposed to the same pyrolysis treatment and was then heated for $2 \mathrm{~h}$ at $950{ }^{\circ} \mathrm{C}$. They then measured the dispersion of calcium during $\mathrm{CO}_{2}$ gasification of these samples. The dispersion of the pre-heated sample was about $50 \%$ lower than the untreated sample at the beginning of the gasification test and about 65\% lower near the end of the test. This resulted in reduced reactivity for the pre-heated sample. Therefore, their work confirms that dispersion of calcium oxide on high surface area carbon is reduced when it is treated at $950^{\circ} \mathrm{C}$. The char samples that were studied in this publication were heated to $1000^{\circ} \mathrm{C}$ (for a shorter time period), and it is likely that this heat treatment resulted in a similar decrease in dispersion. The most significant difference between the raw char and the heated char was in potassium dispersion, where large particles containing potassium were visible in the heated char which were not observed in the raw char. This indicates that potassium has a high mobility at $1000^{\circ} \mathrm{C}$ on carbon surfaces. It is well known that potassium, which is found in biomass, catalyzes the gasification reactions $[1,10,11,14,15]$. Here, the sintering of such species
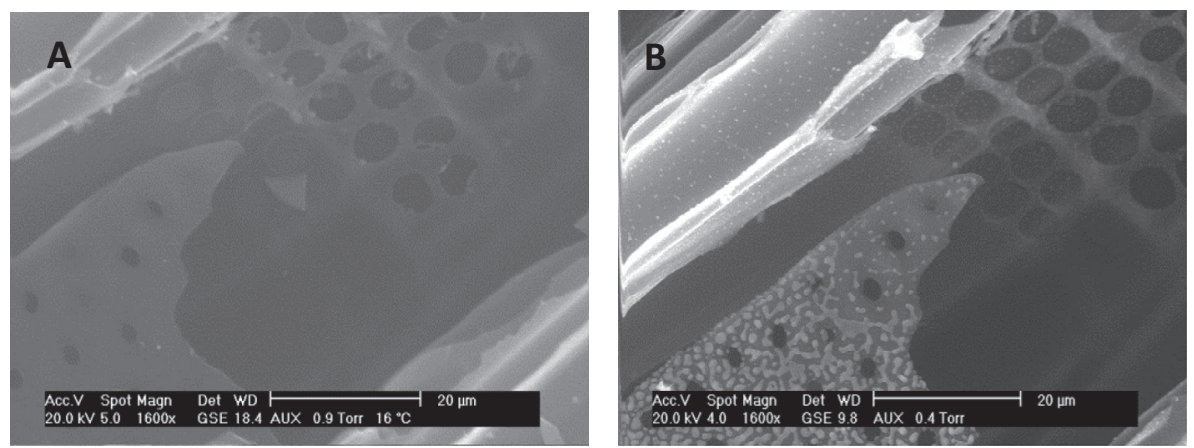

Fig. 8. Char from gasification in steam at $750{ }^{\circ} \mathrm{C}$. (A) Char before heating and (B) char after heating to $1000{ }^{\circ} \mathrm{C}$. Agglomeration of inorganics is visible on the char surface. 
influences the catalytic activity of char for hydrocarbon decomposition reactions.

After the char was thermally treated in $\mathrm{N}_{2}$ at $1000^{\circ} \mathrm{C}$ to allow agglomeration of inorganics, the activity of the treated char was compared to the raw char for methane cracking at $700{ }^{\circ} \mathrm{C}$ in $22 \%$ $\mathrm{CH}_{4}$ (balance $\mathrm{N}_{2}$ ). Results are shown in Fig. 9. These reaction conditions were chosen because at these conditions there were no measurable differences in catalytic activity based on differing surface area. For example, no measurable difference in $\mathrm{H}_{2}$ production was detected when comparing the catalytic activity of char made at $920^{\circ} \mathrm{C}$ or $750{ }^{\circ} \mathrm{C}$ which had a $30 \%$ difference in surface area. The heat treatment at $1000{ }^{\circ} \mathrm{C}$ resulted in a decrease in surface area by approximately $30 \%$, so it was important to operate at reaction conditions where this would not significantly affect the performance. Differences in performance of catalysts with different surface areas are observed at temperatures above $800^{\circ} \mathrm{C}$. This may be due to the low conversions at lower temperatures, which resulted in small differences in performance that were within the measurement error of the system.

The molar concentration of $\mathrm{H}_{2}$ produced using char with high and low dispersion of inorganics are shown in Fig. 9. The activity of the modified char sample was approximately $60 \%$ of that of the raw char. This indicates that gasification conditions will affect catalytic activity of the char not only due to the influence on surface area but also due to the influence on the inorganic sites. The decrease in catalytic activity is likely due to a reduction in dispersion of inorganics and possibly a change in their chemical states. In addition, carbon sites on the surface have been covered by the oxide film, which also decreases catalytic activity. This demonstrates the importance of the physical and chemical states of the inorganics on the catalytic activity of the char. It is clear that the highly dispersed inorganics, and the availability of the carbon surface in the raw char sample improve the catalytic activity of the char. While obtaining high dispersion of inorganics on a support material can be difficult to achieve, the gasification process creates char with highly dispersed inorganic elements on the surface, which is beneficial in catalytic processes.

This is important to understand when using char from gasification processes as a catalyst. The mobility, and consequently the dispersion, of inorganics on the surface depends on the reaction conditions. For example, gasification in air involves reactions that are primarily exothermic whereas gasification with steam or $\mathrm{CO}_{2}$ have endothermic reactions, which could result in significant temperature differences at the site where the reaction takes place. If the inorganics are active sites for exothermic reactions during

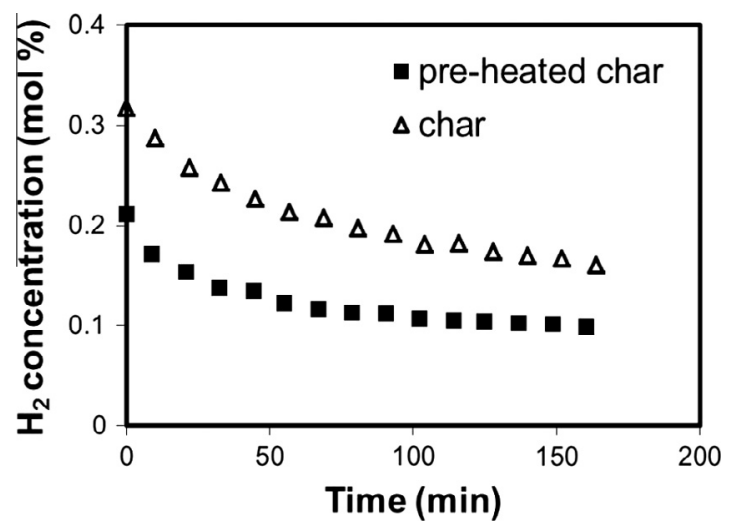

Fig. 9. $\mathrm{H}_{2}$ production from catalytic decomposition of methane at $700{ }^{\circ} \mathrm{C}$ for char and char that had been pre-heated at $1000{ }^{\circ} \mathrm{C}$, resulting in decreased dispersion of inorganics on the char surface. High dispersion of inorganics improves char catalytic activity. gasification then the temperature at the sites will be higher which may increase mobility of the inorganics, leading to agglomeration. Gasification processes which are at temperatures above $1000^{\circ} \mathrm{C}$, and specifically processes using steam, are much more likely to produce char where the inorganics are not highly dispersed on the surface. This will lead to lower catalytic activity. However, while it is common for supported metal catalysts to experience sintering at temperatures such as 750 or $920^{\circ} \mathrm{C}$, this research shows that the gasification process maintains a high dispersion of the catalytic elements which contribute to the catalytic activity of the char.

\subsection{Influence of surface oxygen on catalytic activity}

As discussed in Section 1.4, oxygen functional groups can play a role in catalytic activity of carbon materials. Therefore functional groups on the char surface were studied. The oxygen functional groups were characterized using TPD, and Fig. 10 shows the TPD profiles ( $\mathrm{CO}$ and $\mathrm{CO}_{2}$ desorption as a function of temperature) for four char samples $\left(\mathrm{CO}_{2}-750-30, \mathrm{CO}_{2}-920-30, \mathrm{HO}-750-30\right.$, $\mathrm{H}_{2} \mathrm{O}-750-60$ ). The samples contain both acidic and basic sites, as indicated by the $\mathrm{CO}_{2}$ and $\mathrm{CO}$ peaks. The TPD profiles are very similar for all four samples. The $\mathrm{CO}_{2}$ peak at approximately $350^{\circ} \mathrm{C}$ is typically associated with lactones or carboxylic groups, indicating that char has acid sites [25]. Acid sites are known to play a role in catalytic reactions, specifically in cracking reactions [16]. A broad peak is also observed at $700{ }^{\circ} \mathrm{C}$, which corresponds to carboxylic anhydrides [25]. Basic peaks are also observed, as indicated by the $\mathrm{CO}$ peak at $1000^{\circ} \mathrm{C}$ which is associated with carbonylic, quinonic, and pyrone structures [25]. It is possible that some $\mathrm{CO}_{2}$ was released due to decomposition of inorganic carbonates. However, the inorganics make up only $\sim 2 \%$ of the char, whereas the mass loss of the char was measured to be $\sim 20 \%$ when heated to $800{ }^{\circ} \mathrm{C}$ (as reported in a previous publication [9]). Therefore, the majority of $\mathrm{CO}_{2}$ that desorbs does not come from inorganic carbonates but rather is a result of decomposition of functional groups on the char.

The main difference between the TPD profiles was that sample $\mathrm{CO}_{2}-920-30$ had a slightly larger $\mathrm{CO}_{2}$ peak at $750^{\circ} \mathrm{C}$ and a larger $\mathrm{CO}$ peak at $1000^{\circ} \mathrm{C}$. The TPD profiles confirm the presence of oxygen functional groups on the surface, and show that there are both acidic and basic sites on the char surface, which could play a role in its catalytic performance.

Since the char samples made from gasification had very similar quantities and types of oxygen functional groups, it was difficult to understand the role of oxygen groups by only studying these samples. Therefore, oxygen groups were added to the char surface and the catalytic activity of the oxygenated sample was compared to the original char. The char surface was oxygenated via a nitric acid treatment described in Section 2.6. The BET surface area of the modified char sample was $385 \mathrm{~m}^{2} \mathrm{~g}^{-1}$, which is significantly lower than original char, which had a surface area of $687 \mathrm{~m}^{2} \mathrm{~g}^{-1}$. This indicated that the acid treatment had successfully added oxygen groups to the surface, as discussed in Section 2.6. In addition, TPD profiles showed more acidic oxygen groups on the modified char, as shown in Fig. 11.

The influence of oxygen groups was understood by testing the catalytic activity for the methane decomposition reaction. This was done in a flow through reactor at $850^{\circ} \mathrm{C}$, according to the procedure described in Section 2.4. The catalytic activity of the original char sample was compared to the modified char, which had more acidic functional groups. The results, as shown in Fig. 12, indicate that the two samples have the same catalytic activity. This is attributed to the fact that, for reactions taking place at $850^{\circ} \mathrm{C}$, the acidic oxygen groups desorb at temperatures lower than the reaction temperature. Therefore, these groups do not influence on the catalytic activity of char for high temperature 

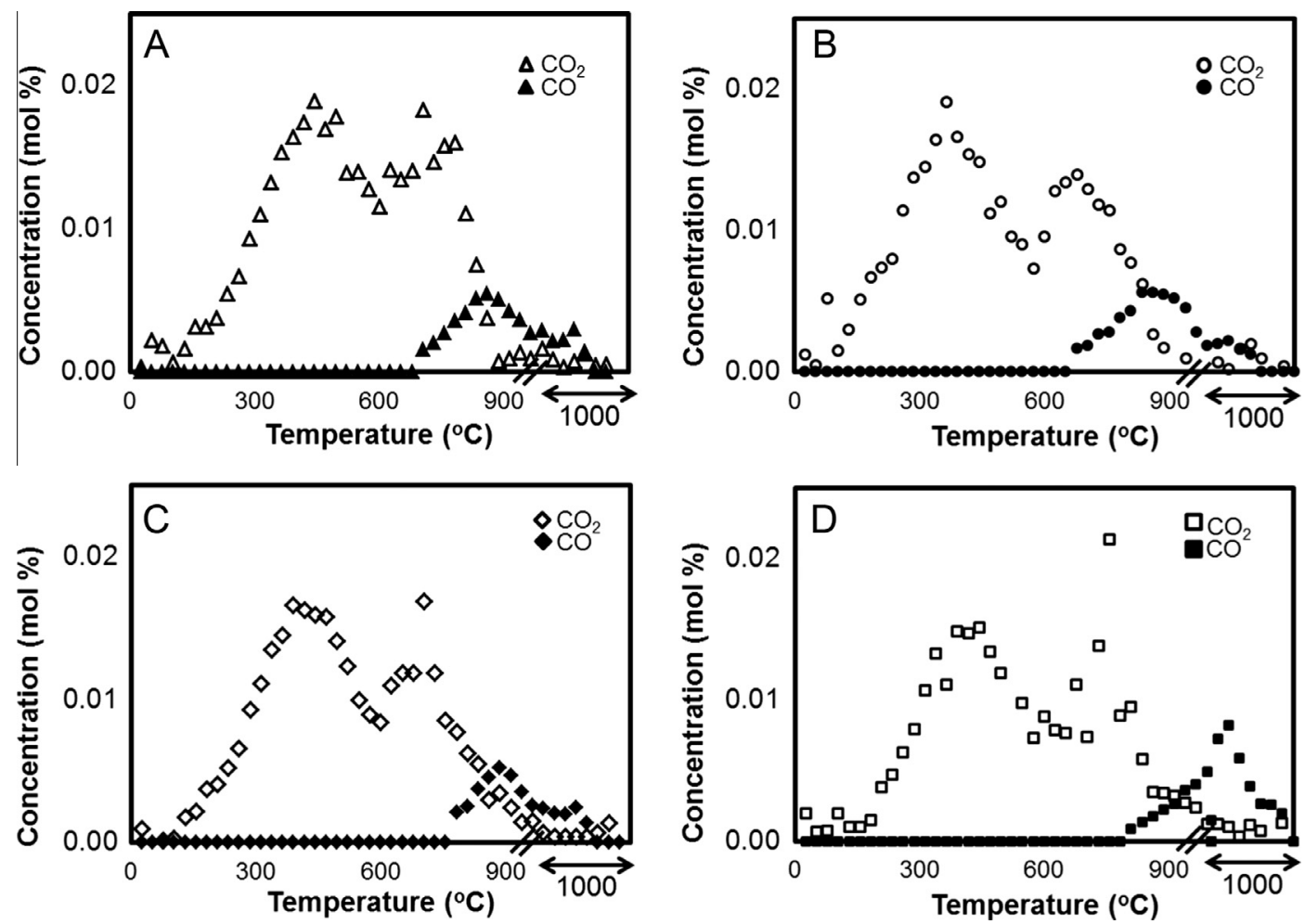

Fig. 10. TPD profiles of four char samples. Temperature was increased to $1000{ }^{\circ} \mathrm{C}$ at $10^{\circ} \mathrm{C} \mathrm{min}^{-1}$ and then held at $1000{ }^{\circ} \mathrm{C}$ for 15 min. Gasification conditions were different for samples A-D. (A) $\mathrm{H}_{2} \mathrm{O}-750-30$, (B) $\mathrm{CO}_{2}-750-30$, (C) $\mathrm{H}_{2} \mathrm{O}-750-60$ and (D) $\mathrm{CO}_{2}-920-30$.
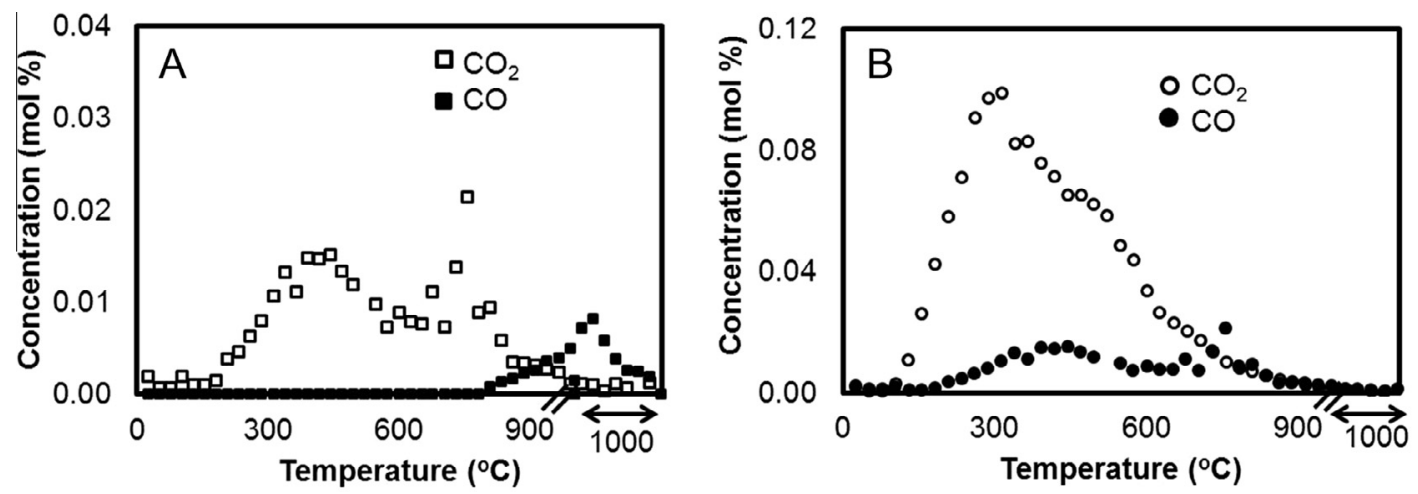

Fig. 11. TPD profiles for char and oxygenated char. Char was heated to $1000{ }^{\circ} \mathrm{C}$ at $10^{\circ} \mathrm{C} \mathrm{min}-1$ and held at $1000{ }^{\circ} \mathrm{C}$ for 15 min. Filled symbols are CO and empty symbols are $\mathrm{CO}_{2}$. (A) Char and (B) char after $\mathrm{HNO}_{3}$ treatment which adds oxygen functional groups to the surface. Note: Scales on figures A and B are different in order to show details.

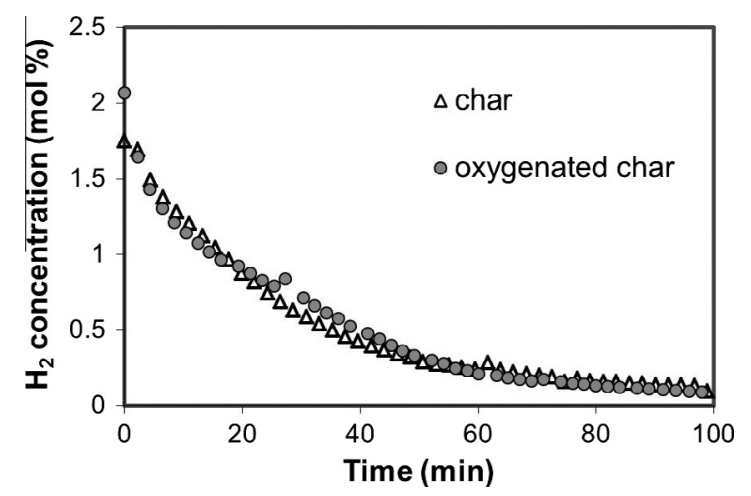

Fig. 12. $\mathrm{H}_{2}$ production from methane decomposition for char and char with oxygen groups added to the surface. Increasing oxygen functionalities does not improve catalytic performance for high temperature reactions. reactions. The basic groups which remain on the char surface at high temperatures may affect the catalytic activity of the char, and is an interesting area for future work.

If char is used as a catalyst in a secondary reactor for processing tars from gasification then $\mathrm{CO}$ and $\mathrm{CO}_{2}$ will be present, since the reactor exhaust will contain a mixture of syngas and tar. The presence of $\mathrm{CO}$ and $\mathrm{CO}_{2}$ will decrease the driving force for the surface functional groups on the char to desorb as $\mathrm{CO}$ and $\mathrm{CO}_{2}$. In these experiments, when the samples were heated in pure nitrogen, the thermodynamic potential supports the release of $\mathrm{CO}$ and $\mathrm{CO}_{2}$, which desorb from the surface. In the secondary reactor, which contains gasification products, the functional groups may not desorb and could impact the catalytic activity of the char at high temperatures. Therefore, the role of oxygen groups will depend on the temperature and reaction environment in which the char is used as a catalyst. 


\section{Conclusions}

This research investigates the use of residual char from biomass gasification as a catalyst. The influence of char composition on its catalytic activity was studied. The char is composed primarily of carbon, measuring approximately $85 \mathrm{~mol} \%$. The other main components are hydrogen (1-2\%), nitrogen (1-2\%), and sulfur $(0.3-1 \%)$, with the balance being oxygen and ash. Inorganics such as $\mathrm{Ca}$, $\mathrm{Na}, \mathrm{K}, \mathrm{Mg}, \mathrm{P}, \mathrm{Si}$, and $\mathrm{Fe}$ were present in the char and char with higher concentrations of inorganics had higher catalytic activity. For example, when char that contained $\sim 2 \%$ inorganics was used as a catalyst, the reaction rate was $16-27 \%$ higher (depending on reaction temperature) than a similar char sample without inorganics. Inorganic elements were highly dispersed in the char, which improved its catalytic activity. When the char was treated at high temperatures, causing inorganics and oxygen to migrate and agglomerate on the surface, the activity was reduced by approximately $40 \%$. The influence of the gasification atmosphere was also observed. It has been shown that agglomeration of inorganics takes place during gasification in $\mathrm{H}_{2} \mathrm{O}$ at $1000^{\circ} \mathrm{C}$ but this is lower during gasification in a $\mathrm{CO}_{2}$ environment. Achieving high dispersion of catalytic material on supports is an important aspect of catalyst synthesis; the gasification process produces char with highly dispersed catalytic elements which is very valuable. The influence of oxygen functional groups on catalytic activity of the char was investigated. Both acidic and basic oxygen groups were observed on the char surface. While these functionalities are important for low temperature applications of carbon based materials, the acidic oxygen groups desorb at temperatures lower than $800^{\circ} \mathrm{C}$, and therefore did not play a role in the catalytic activity of char. The influence of basic oxygen groups on the char's catalytic activity is a subject for future work. The catalytic activity of the char was compared to ash, and the char had significantly higher activity than ash. The carbon serves as a support on which the inorganics can be highly dispersed. The carbon most likely also has catalytic activity, and carbon-metal interactions likely influence the reactions, which is an area for further research. The utilization of char, a by-product of gasification, in catalytic applications can improve the overall efficiency and economics of gasification processes, making it a more viable option for energy recovery from biomass or waste.

\section{Acknowledgements}

This research was supported by the Earth Engineering Center at the City College of New York. The authors thank Alexsandra Guerra for contributing to the experimental work presented in this paper. The authors acknowledge Christine Rolland, Céline Boachon, Sylvie Delconfetto, Sévérine Patry, and Jean Marie Sabathier for assistance with experiments.

\section{References}

[1] Sueyasu T, Oike T, Mori A, Kudo S, Norinaga K, Hayashi J. Simultaneous steam reforming of tar and steam gasification of char from the pyrolysis of potassium-loaded woody biomass. Energy Fuels 2012:26:199-208.

[2] Mun TY, Kim JO, Kim JW, Kim JS. Influence of operation conditions and additives on the development of producer gas and tar reduction in air gasification of construction woody wastes using a two-stage gasifier. Bioresour Technol 2011:102:7196-203.

[3] Striugas N, Zakarauskas K, Stravinskas G, Grigaitiene V. Comparison of steam reforming and partial oxidation of biomass pyrolysis tars over activated carbon derived from waste tire. Catal Today 2012;196:67-74.

[4] Wang D, Yuan WQ Ji W. Char and char-supported nickel catalysts for secondary syngas cleanup and conditioning. Appl Energy 2011;88:1656-63.

[5] El-Rub ZA, Bramer EA, Brem G. Experimental comparison of biomass chars with other catalysts for tar reduction. Fuel 2008;87:2243-52.
[6] Min ZH, Yimsiri P, Asadullah M, Zhang S, Li CZ. Catalytic reforming of tar during gasification. Part II. Char as a catalyst or as a catalyst support for tar reforming. Fuel 2011;90:2545-52.

[7] Chaiwat W, Hasegawa I, Mae K. Alternative reforming methods of primary tar released from gas treatment of biomass at low temperature for development of pyrolysis/gasification process. Ind Eng Chem Res 2010;49:3577-84.

[8] Xiao XB, Cao JP, Meng XL, Le DD, Li LY, Ogawa Y, et al. Synthesis gas production from catalytic gasification of waste biomass using nickel-loaded brown coal char. Fuel 2013;103:135-40.

[9] Klinghoffer NB, Castaldi MJ, Nzihou A. Catalyst properties and catalytic performance of char from biomass gasification. Ind Eng Chem Res 2012;51: $13113-22$.

[10] Dupont C, Nocquet T, Da Costa JA, Verne-Tournon C. Kinetic modelling of steam gasification of various woody biomass chars: Influence of inorganic elements. Bioresour Technol 2011;102:9743-8.

[11] Yip K, Tian FJ, Hayashi J, Wu HW. Effect of alkali and alkaline earth metallic species on biochar reactivity and syngas compositions during steam gasification. Energy Fuels 2010;24:173-81.

[12] Kowalski T, Ludwig C, Wokaun A. Qualitative evaluation of alkali release during the pyrolysis of biomass. Energy Fuels 2007;21:3017-22.

[13] Keown DM, Favas G, Hayashi JI, Li CZ. Volatilisation of alkali and alkaline earth metallic species during the pyrolysis of biomass: differences between sugar cane bagasse and cane trash. Bioresour Technol 2005;96:1570-7.

[14] Marquez-Montesinos F, Cordero T, Rodriguez-Mirasol J, Rodriguez JJ. $\mathrm{CO}_{2}$ and steam gasification of a grapefruit skin char. Fuel 2002;81:423-9.

[15] Habibi R, Kopyscinski J, Masnadi MS, Lam J, Grace JR, Mims CA, et al. Cogasification of biomass and non-biomass feedstocks: synergistic and inhibition effects of switchgrass mixed with sub-bituminous coal and fluid coke during $\mathrm{CO}_{2}$ gasification. Energy Fuels 2013;27:494-500.

[16] Min Zhenhua, Yimsiri Piyachat, Asadullah Mohammad, Zhang Shu, Li ChunZhu. Catalytic reforming of tar during gasification. Part II. Char as a catalyst or as a catalyst support for tar reforming. Fuel 2011;90(7):2545-52.

[17] Min Zhenhua, Zhang Shu, Yimsiri Piyachat, Wang Yi, Asadullah Mohammad, Li Chun-Zhu. Catalytic reforming of tar during gasification. Part IV. Changes in the structure of char in the char-supported iron catalyst during reforming. Fuel 2013;106:858-63.

[18] Bartholomew CH, Farrauto RJ. Fundamentals of industrial catalytic processes. Wiley-Interscience; 2006.

[19] Boehm HP. Some aspects of the surface-chemistry of carbon-blacks and other carbons. Carbon 1994;32:759-69.

[20] Serp P, Figueiredo JL. Carbon materials for catalysis. Wiley; 2009.

[21] Lee WH, Reucroft PJ. Vapor adsorption on coal- and wood-based chemically activated carbons: (I) Surface oxidation states and adsorption of H2O. Carbon 1999;37:7-14.

[22] Eberhardt TL, Pan H. Elemental analyses of chars isolated from a biomass gasifier fly ash. Fuel 2012;96:600-3.

[23] Ahumada E, Lizama H, Orellana F, Suarez C, Huidobro A, Sepulveda-Escribano A, et al. Catalytic oxidation of $\mathrm{Fe}(\mathrm{II})$ by activated carbon in the presence of oxygen. Effect of the surface oxidation degree on the catalytic activity. Carbon 2002;40:2827-34.

[24] Teng HS, Tu YT, Lai YC, Lin CC. Reduction of $\mathrm{NO}$ with $\mathrm{NH}_{3}$ over carbon catalysts - The effects of treating carbon with $\mathrm{H}_{2} \mathrm{SO}_{4}$ and $\mathrm{HNO}_{3}$. Carbon 2001;39: $575-82$.

[25] Szymanski GS, Karpinski Z, Biniak S, Swiatkowski A. The effect of the gradual thermal decomposition of surface oxygen species on the chemical and catalytic properties of oxidized activated carbon. Carbon 2002;40: 2627-39.

[26] Chen CH, Xu JQ, Jin MM, Li GY, Hu CW. Direct synthesis of phenol from benzene on an activated carbon catalyst treated with nitric acid. Chin J Chem Phys 2011;24:358-64.

[27] Pradhan BK, Sandle NK. Effect of different oxidizing agent treatments on the surface properties of activated carbons. Carbon 1999;37:1323-32.

[28] Ouyn DM, Wu HW, Bhattacharya SP, Li CZ. Volatilisation and catalytic effects of alkali and alkaline earth metallic species during the pyrolysis and gasification of Victorian brown coal. Part II. Effects of chemical form and valence. Fuel 2002;81:151-8.

[29] Bourgel C, Veron E, Poirier J, Defoort F, Seiler JM, Peregrina C. Behavior of phosphorus and other inorganics during the gasification of sewage sludge. Energy Fuels 2011;25:5707-17.

[30] Di Felice L, Courson C, Niznansky D, Foscolo PU, Kiennemann A. Biomass gasification with catalytic tar reforming: a model study into activity enhancement of calcium- and magnesium-oxide-based catalytic materials by incorporation of iron. Energy Fuels 2010;24:4034-45.

[31] Devi L, Ptasinski KJ, Janssen F. A review of the primary measures for tar elimination in biomass gasification processes. Biomass Bioenergy 2003;24:125-40.

[32] Abu El-Rub Z, Bramer EA, Brem G. Review of catalysts for tar elimination in Biomass gasification processes. Ind Eng Chem Res 2004;43:6911-9.

[33] Al-Hassani AA, Abbas HF, Wan Daud WMA. Hydrogen production via decomposition of methane over activated carbons as catalysts: Full factorial design. Int J Hydrogen Energy 2014;39:7004-14.

[34] Serrano DP, Botas JA, Fierro JLG, Guil-Lopez R, Pizarro P, Gomez G. Hydrogen production by methane decomposition: Origin of the catalytic activity of carbon materials. Fuel 2010;89:1241-8. 
[35] Hsu LY, Teng HS. Catalytic NO reduction with $\mathrm{NH}_{3}$ over carbons modified by acid oxidation and by metal impregnation and its kinetic studies. Appl Catal BEnviron 2001;35:21-30.

[36] Illan-Gomez MJ, Raymundo-Pinero E, Garcia-Garcia A, Linares-Solano A, de Lecea CSM. Catalytic NOx reduction by carbon supporting metals. Appl Catal BEnviron 1999;20:267-75.
[37] Cazorla-Amoros D, Linaressolano A, Delecea CS, Yamashita H, Kyotani T, Tomita A, et al. XAFS and thermogravimetry study of the sintering of calcium supported on carbon. Energy Fuels 1993;7:139-45. 